\title{
El Salvador en la postguerra: de la violencia armada a la violencia social
}

\section{Introducción}

En 1992, con la firma de los Acuerdos de Paz, se puso fin a casi doce años de guerra civil en El Salvador. Una década de violencia armada llegaba a su término y se iniciaba una en la que el exterminio militar del enemigo político perdía cualquier legitimidad. Atrás quedaban, como un recuerdo, los desaparecidos, los asesinatos colectivos, los "ajusticiamientos" y las prácticas intimidatorias de los grupos paramilitares - los escuadrones de la muerte- que hicieron del terrorismo sus modus vivendi. El principal eje de la violencia que dominó a El Salvador durante más de diez años -el enfrentamiento militar abierto- de pronto dejaba de existir, con lo que se daba pie a una situación de optimismo social generalizado: terminada la guerra, se pensaba, las posibilidades de una convivencia social relativamente pacífica se volvían más plausibles.

Era evidente que esa convivencia no sería fácil, sobre todo porque inmediatamente después de firmados los Acuerdos de Paz se produjeron algunos asesinatos cuyas implicaciones políticas fueron inocultables. Pero, de algún modo, eso guardaba relación con ese pasado reciente de polarización política'que comenzaba a ser superado. También estaba el problema de la desarticulación de los cuerpos de seguridad (Policía Nacional, Guardia Nacional y Policía de Hacienda) que, aparentemente, sería resuelto sin mayores complicaciones para el país. La entrega y destrucción de armas de guerra, la desmovilización de los combatientes del Frente Farabundo Martí para la Liberación Nacional (FMLN), la reducción del ejército y la incorporación de los ex combatientes de ambos bandos a la vida civil, aunque presentaban mayor dificultad - por la calendarización a la que estaban sujetas - no daban señales de complicar esa fase de la transición salvadoreña iniciada en 1992. El panorama socio-político, pues, no se prestaba a pesimismo alguno. La violencia militar y paramilitar se había terminado y el país estaba listo para avanzar en el proceso de institucionalización democrática planteado en los Acuerdos de Paz.

- Director del Centro de Información, Documentación y Apoyo a la Investigación (CIDAI), de la Universidad Centroamericana "José Simeón Cañas". 
Sin embargo, el desarrollo posterior de los acontecimientos puso serios reparos a aquel optimismo. Una grave situación de violencia social se suscitó en El Salvador creando un clima de alarma generalizada tanto en los círculos de gobiemo como en la sociedad civil; tampoco fueron ajenos a este "clima de violencia" en la postguerra organismos internacionales como la Organización Panamericana de la Salud (OPS) y el Banco Interamericano de Desarrollo (BID), instituciones que, en los últimos dos años, se han preocupado por incentivar aproximaciones más sistemáticas a la problemática de la violencia social en El Salvador.

Así, mientras que el gobierno -a través del Ministerio de Seguridad Pública, la Policía Nacional Civil y los tribunales- ha hecho del problema de la violencia algo puramente delincuencial $-\mathrm{y}$ que, en consecuencia, tiene que ser enfrentado con medidas coercitivas, como la pena muerte-, la Iglesia católica se ha mostrado preocupada por la "cultura de la violencia" que cotidianamente cobra víctimas inocentes en diversas zonas del país. Con todo, pese a la alarma generalizada en tomo a la situación de violencia —expresada, entre otras cosas, en asesinatos familiares, secuestros, extorsiones, violaciones y enfrentamientos callejeros entre pandillas juveniles- las instancias gubemamentales responsables de la seguridad ciudadana y la aplicación de justicia - PNC, Fiscalía General de la República, Corte Suprema de Justicia y Procuraduría de para la Defensa de los Derechos Humanos - no llevan hasta el día hoy un registro sistemático y completo sobre los diferentes tipos de violencia y sus víctimas.

Fue justamente esa constatación la que llevó al Banco Interamericano de Desarrollo (BID) a promover una investigación que diera cuenta, por lo menos provisionalmente, de la magnitud y los costos de la violencia en El Salvador después de la firma de los Acuerdos de Paz. Un esfuerzo similar, auspiciado por la Organización Panamericana de la Salud (OPS), apuntaba a dar cuenta del fenómeno de la violencia mediante una encuesta de victimización. Este trabajo, recientemente finalizado, estuvo a cargo del Instituto Universitario de Opinión Pública (IUDOP); la investigación promovida por el BID, de la que ya se ha elaborado una versión preliminar, corrió a cargo tanto del IUDOP como del Centro de Información, Documentación y Apoyo a la Investigación (CIDAI), también de la Universidad Centroamericana "José Simeón Cañas".

El presente artículo se apoya en algunos de los datos sobre la magnitud de la violencia recolectados para la investigación del BID. Su propósito es describir muy someramante - y a partir de los datos disponibles hasta ahora- la situación de violencia en El Salvador de la postguerra. Esta situación puede ser tipificada como de "violencia social", pues la misma ya no es una violencia política o militar, sino algo que afecta e involucra a grupos sociales con motivaciones diversas, pero desligadas absolutamente de la política o la ideología: a) delincuenciales -el crimen organizado y el robo tradicional-; b) territoriales y simbólicas - las pandillas o "maras"-; c) económicas — los desmovilizados del ejército y del FMLN; las trabajadoras de la maquilas-; venganza -enfrentamientos entre familias-; y culturales -el "valeverguismo" salvadoreño, la matonería, el alarde de fuerza, "ser más vivos" que los demás-. 
En definitiva, los salvadoreños hemos tenido que enfrentamos en la postguerra con una situación de violencia cuya complejidad ha hecho que el optimismo acerca de una convivencia social pacífica en el futuro inmediato sea una cada vez más insostenible. En la actualidad, reina por doquier un pesimismo desalentador.-Prácticamente nadie estaba preparado para entender o, muchos menos, poner remedio a la situación de violencia que se impuso después de terminada la guerra civil. En este contexto es que se han comenzado a dar los primeros pasos para comprender con un mínimo de rigor el problema de la violencia en nuestro país.

A continuación, presentamos un avance de los logrado hasta este momento en materia de investigación sobre la violencia en El Salvador. Antes de ello, sin embargo, haremos una somera caracterización del entomo socio-cultural y económico salvadoreño en los años $90 \mathrm{y}$, en segundo lugar, expondremos algunas nociones teóricas que nos ayuden a situar el problema que nos ocupa en una perspectiva que vaya más allá de los meros registros empíricos y que, además, nos permitan aclarar nuestra noción de "violencia social" como irreductible a la "violencia delincuencial". Posteriormente, pasaremos a la exposición de algunos de los resultados de la investigación preparada para el BID.

\section{El Salvador en los años 90}

Un diagnóstico socio económico y cultural de El Salvador en los años 90 no puede obviar la segmentación que lo caracteriza y que en conjunto caracteriza a las sociedades latinoamericanas. Como ha dicho N. Lechner, "la liberalización de los mercados, la apertura del comercio exterior, la reducción del gasto fiscal y la privatización de las empresas públicas, provocan una drástica desorganización de la vida social; junto a la acelerada globalización de los circuitos comerciales financiero, estilos de vida y ámbitos culturales tienen lugar en un acentuado proceso de segmentación de cada sociedad. En nuestra región las dinámicas de la economía capitalista de mercado se imponen brutalmente, apenas amortiguadas por mecanismos compensatorios y sistema de seguridad social. Los lazos afectivos y las formas simbólicas de comunidad se disgregan"2. Una pregunta pertinente en el caso de El Salvador es si, en la postguerra, no estamos ante un grave problema de integración social que es expresa, entre otros aspectos, en la segregación educativa y socio-laboral de sectores importantes de la población, entre los que la juventud ocupa un lugar de primera importancia.

Precisamente, uno de los rasgos de El Salvador en la actualidad lo constituye la juventud marginal, que se ve forzada a sobrevivir violentando el orden social del cual ha sido excluida. Ciertamente, tanto la marginalización de la juventud como la juventud marginal no son fenómenos nuevos ni recientes en El Salvador. Si por algo se han caracterizado históricamente las estructuras socio-laborales y educativas salvadoreñas es precisamente por su tendencia estructural a excluir a la juventud de la formación y los beneficios a los que tienen derecho los jóvenes como seres humanos y como ciudadanos. Lo ahterior contribuye a explicar por qué éstos han sido protagonistas - junto con los campesinos y los 
obreros- en los principales movimientos socio-políticos del país a lo largo del siglo XX. El inconformismo juvenil ha tenido mucho que ver en ello, pero el mismo se vio alentado y justificado por la exclusión que muchos de los inconformes vivieron en came propia ${ }^{3}$.

El Salvador de la postguerra está montado sobre unas estructuras socio-económicas que marginan, junto a otros grupos sociales, a la juventud. Pero la juventud marginada no sólo, obviamente, no es la misma de las tres últimas décadas, sino que el horizonte de sus demandas es cualitativamente distinto al de aquélla. Y es que si en lo esencial la juventud marginal y/o constestataria de la preguerra encauzó sus demandas a través de la organización político-revolucionaria, la juventud marginal de la postguerra lo hace, por ejemplo, a través de la organización en "maras" o pandillas", al margen de cualquier creencia en la revolución o el socialismo. Las maras no sólo son manifestación de un grave e irresuelto problema de integración social, sino expresión de una importante y novedosa mutación cultural que se está operando en la juventud marginal. Las maras no demandan una cuota de poder político, sino un espacio territorial propio en el cual poder reivindicar su propia identidad grupal e individuals.

El Salvador en los 90 está en pleno proceso de transición a la democracia. Este proceso tiene un eje político que ciertamente es el que predomina: transición democrática significa, ante todo, la superación del sistema político autoritario que estuvo vigente en el país hasta el golpe de Estado de octubre de 1979, fecha en que se inició un continuado proceso de liberalización política que llega hasta nuestros días. En los Acuerdos de Paz, suscritos por el gobiemo de Alfredo Cristiani y el FMLN en enero de 1992, están plasmadas las líneas maestras para la construcción de un orden democrático en el país. Con estos documentos, los principales actores socio-políticos aceptaron que la competencia electoral, el pluralismo ideológico y el consenso político constituyen elementos cruciales para una convivencia más civilizada entre los salvadoreños. Pero se trata de una aceptación de la democracia política, no de una democracia social que como tal no fue abordada con la profundidad merecida en los Acuerdos de Paz.

De aquí que en El Salvador, al igual que en otros palses latinoamericanos que acusan severos déficit de democracia social - por ejemplo, graves desigualdades económico-sociales y desintegración social y cultural-, el problema mayor es cómo fortalecer su aparato productivo y cómo hacer que los logros económicos se traduzcan en mayores niveles de justicia y equidad. El problema es cómo conciliar economía y política, democracia política y democracia social, a sabiendas que una y otra no van siempre de la mano, pero sin dejar se reconocer que su se quiere una sociedad más estable y menos conflictiva es preciso lograr el fortalecimiento recíproco de ambas. El Salvador de los 90 no es ajeno a este desafío.

\section{Sociedad y violencia, algunas nociones téricas}

Para acercamos al problema de la violencia como un problema teórico vamos a avanzar algunas reflexiones sobre el tema que de algún modo son ya parte 
de la tradición sociológica. Ante todo, un punto de partida inexorable consiste en reconocer que, en las relaciones sociales, se generan relaciones de dependencia entre los individuos y los grupos no en razón de su voluntad, sino en razón de las jararquías impuestas por la propia estructura social. En segundo lugar, las relaciones sociales son relaciones de poder, esto es, relaciones en las que los sujetos que interactúan van cargados con una serie de posesiones - su propio cuerpo, su saber, su tradición familiar, sus recursos económicos y políticosque no sólo entran en juego en aquella interacción, sino que pueden marcar diferencia notables entre los individuos. En otras palabras, el ejercicio del poder y la dependencia de unos individuos respecto de otros son elementos ineludibles en las relaciones sociales; poseen una objetividad que se deriva de la estructura social y de las jerarquías que la misma impone.

Por lo demás, las relaciones de dependencia y poder que se establecen entre los individuos y los grupos no son idénticas en todos los casos. Estas varían y son tan diversas según sea el capital simbólico y material de los individuos y los grupos, el espacio en el cual éstos interactúan y el rol que desempeñan. En lo que atañe al capital simbólico y material, una cosa es la relación de dependencia y poder que se manifiesta en el comportamiento de un empresario ante el personal de producción de su fábrica que ante el personal técnico o secretarial. Asimismo, el comportamiento del empresario es distinto si se trata de una corporación en la cual es el socio mayoritario. Las relaciones de dependencia y poder entre los accionistas minoritarios y el personal técnico y los obreros, o al interior de estos dos grupos serán también diferentes.

El espacio de interacción entre los actores sociales influye decisivamente en las relaciones de dependencia y poder. Más aún, es un espacio en el que además cristalizan determinadas relaciones de dependencia. Volviendo al ejemplo anterior, uno es el espacio financiero, en el cual los accionistas "dominan" al conjunto de los actores que se desenvuelven en el espacio global de la empresa; otro es el espacio de la producción, "dominado" por los técnicos; otro es el espacio de las relaciones públicas, "dominado" por lo ejecutivos (o ejecutivas); otro es el espacio de la seguridad, "dominado" por sus guardianes; por último está el espacio de la máquina, "dominado" por los obreros.

Ciertamente, el capital simbólico y material hace posible que los actores puedan ocupar un espacio determinado. Asimismo, estos actores ocupan, de hecho, espacios distintos en razón de que el capital simbólico y material está distribuido desigualmente en la sociedad. Pero ese espacio no se "ocupa" de cualquier forma: se hace a partir de un rol determinado, que exige un ejercicio especifico del poder simbólico y material, el cual se posee en el contexto del espacio ocupado.

En resumen, las relaciones sociales no sólo son relaciones en las que interactúan actores con un capital material y simbólico desigual, sino que las mismas se establecen en espacios determinados, en los cuales los actores asumen roles también determinados, los cuales pueden ser desempeñados en razón del capital simbólico y material que se posee, pero que decantan el modo cómo puede y debe ser utilizado ese capital. Asimismo, en una sociedad determinada, 
las diferencias de capital simbólico y material de cada uno de los actores sociales -y de los grupos de actores entre sí- y los distintos espacios que las mismas les permiten ocupar y dominar, asumiendo determinados roles, dan lugar a una jerarquización social, cuya objetividad es indudable. Es decir, dan lugar a una estructuración objetiva de las relaciones sociales como relaciones de dependencia entre unos actores y otros -entre unos grupos y otros-, en las cuales las diferencias de capital simbólico y material posibilitan el "dominio" de unos actores y grupos sobre otros, lo cual es legitimado a través de los diferentes status establecidos jerárquicamente en la sociedad.

¿Cómo ilumina la discusión anterior a la realidad salvadoreña de la postguerra? Pues bien, en El Salvador, como en cualquier otra sociedad segmentada por razones estructurales, hay una distribución desigual del capital simbólico y material entre los individuos y los grupos. Hay también diversas relaciones de dependencia optre éstos, las cuales se establecen en espacios determinados, "dominados" por individuos y grupos en razón del capital simbólico y material que les es propio y según los requerimientos específicos del rol desempeñado. Hasta aquí, pues, estamos ante unas relaciones de poder y de dependencia entre los individuos y los grupos que conforman nuestra sociedad, cuya objetividad no puede ser negada.

Pero para entender a El Salvador de postguerra no basta con eso, pues individuos y grupos, en los distintos espacios en los cuales están en condiciones para ejercer el poder que poseen, no sólo lo ejercen de hecho, sino que lo reafirman de un modo sumamente exacerbado, lo cual llega hasta limites verdaderamente patológicos. Es decir, el "otro" debe saber que está en manos del que domina la situación y, además, que no puede hacer nada para revertirla. Y quien domina la situación -el espacio de que se trate- se las arregla para que los dominados en ese espacio asuman que eso es ineludiblemente asf. Hay, por tanto, una reafirmación del poder que ya objetivamente se tiene; y esa reafirmación camina muchas veces por el ejercicio de diferentes tipos de violencia, Ios cuales pueden llegar alcanzar niveles extremos de barbarie, como lo muestran los diferentes casos de asesinatos colectivos de familias, los asesinatos de menores de edad o las violaciones de que son víctimas niños y niñas impúberes.

En El Salvador estamos ante una reafirmación patológica del poder —patológica porque necesita muchas veces de la violencia más brutal para imponerseque permea los poros de nuestra sociedad, y que se desprende, como en un efecto de cascada, del ejercicio del poder que caracteriza a las élites dominantes en el país. En efecto, nuestras élites no sólo detentan objetivamente el poder económico y político, sino que lo reafirman - necesitan reafimarlo- violentamente. Esta violencia alimenta la violencia cotidiana de nuestra sociedad y, además, necesita de ella para legitimarse y autorreproducirse.

Las hipótesis que pueden aventurarse para explicar por qué ello es así son muchas, pero entre ellas no puede dejar de mencionarse aquella que alude a cómo el ejercicio del poder de nuestras élites políticas y económicas ha carecido históricamente de una base de sustentación simbólica, lo cual no les ha permitido —n la terminologia gramsciana - "dirigir" la sociedad, aunque sí "dominar- 
la". Es decir, là fuerza ha sido, desde siempre, el complemento de un poder que objetivamente se ha poseído, pero que se ha sabido no aceptado por quienes están excluidos de él. Y, en cuanto se sabe no aceptado, es cree siempre en peligro, siempre tambaleante, siempre desafiado $y$, en consecuencia, siempre necesitado de un recurso que "recuerde» a los dominados quiénes son los que de hecho mandan. Ese recurso ha sido la violencia en sus diversas manifestaciones.

En nuestro país, los grupos dominantes han sido incapaces, quizás por su voracidad, de comprometerse con el bienestar de los sectores populares. Estos últimos han sido vistos, desde la cima del poder político y económico, como personas de segunda o tercera categoría, como recurso de explotación y, por supuesto, como resentidos y siempre dispuestos al robo, al vandalismo y al desorden. La prepotencia y la matonería se han propagado desde los círculos del poder como el único mecanismo válido para tratar con un pueblo de tan baja condición. La violencia ha sido el complemento "natural" de un poder económico-politico que no requiere ser aceptado y reconocido por unos ciudadanos inexistentes, es decir, que no necesita de una legitimidad cuyos valores sean el consenso, el respeto y la tolerancia, porque basta y sobra con la pistola al cinto, un juego de cadenas de oro al cuello, un buen fajo de billetes en la billetera y un par de matones armados de compañía.

La cultura de la violencia es algo característico de la sociedad salvadoreña de la postguerra, pero el fenómeno ni es nuevo ni obedece a un fatum natural ni es patrimonio de los sectores populares. Pensar que la cultura de la violencia es exclusiva de la postguerra es desconocer uno de los rasgos esenciales del ejercicio del poder, que ha caracterizado históricamente a las élites del país; creer que los salvadoreños estamos condenados a vivir ad eternum en la violencia es desconocer - y no preocuparse por entender - las razones históricas del problema; pensar que la violencia es patrimonio de los sectores populares es obviar que buena dosis de la misha la misma se propaga desde los círculos del poder.

En el momento actual, estilos arraigados de violencia se han conjugado con otros aprendidos (y alimentados) durante la guerra, dando lugar a un complejo de violencia que no sólo afecta al conjunto de la sociedad, sino que hace a cada uno de los salvadoreños agente activo en su reproducción. En ese complejo de violencia, los actividades delincuenciales -en las cuales el ejercicio de la violencia es un medio para obtener algún tipo de beneficio- ocupan un lugar de primera magnitud, pero no lo agotan. Existen abundantes casos de violencia en los cuales ésta, más que ser un medio, es un fin: el acto violento se agota en sí mismo, es decir, en la satisfacción que deja en el victimario el sufrimiento de su víctima. O están también los casos, que son más norma que excepción, en los que el delincuente, para conseguir una beneficio insignificante, aplica medidas extremas de violencia contra sus víctima, que incluso no está a salvo aún cuando haya satisfecho la demanda del agresor.

A esa violencia -que puede alcanzar niveles extremos de brutalidad - $\sin$ motivaciones políticas o materiales explícitas o implícitas y que es ejercida no sólo por grupos específicos de la sociedad, sino por una gran mayoría de salvadoreños, cotidianamente, en el hogar, en el trabajo, en la calle, en los lugares de 
recreación, bares, etc., a esa violencia es a la que caracterizamos como violencia social, por contraposición a otras formas de violencia como la política - que caracterizó al país hasta la firma de los Acuerdos de Paz (no por ser la única, sino por ser la dominante) o la violencia delincuencial cuyas motivaciones "instrumentales" permiten que sea fácilmente circunscrite sociológica y jurídicamente.

\section{Magnitud de la violencia}

Es un hecho que la violencia ha alcanzado niveles extremadamente graves en El Salvador. Instituciones públicas y privadas han manifestado su preocupación sobre el problema en repetidas ocasiones. Sin embargo, no se conocen estudios sistemáticos que, apoyados en una información cuantitativa suficientemente amplia, ofrezcan una visión global del problema de la violencia. Una de las razones de la inexistencia de tales estudios estriba en las limitaciones de los registros de violencia que llevan las instituciones gubemamentales responsables de ellos. En su gran mayoría, esos registros son parciales —en el sentido de no recoger más que casos específicos de violencia-, temporalmente limitados - no van más allá de los últimos tres años- y faltos de rigor —en muchos casos los datos de una misma institución sobre un mismo tema pueden variar significativamente sin que sea claro el motivo de la variación.

De este modo, cualquier esfuerzo serio encaminado a explicar el fenómeno de la violencia en El Salvador tiene que partir de una base cuantitativa mínimamente consistente. Los datos que se presentan a continuación constituyen un esfuerzo inicial por ir dando un carácter más sistemático a los datos que sobre violencia existen en nuestro país. El trabajo de búsqueda, depuración y cotejo de los registros de las diferentes instituciones no ha sido fácil; y aunque ciertamente lo que aquí se presenta es un primer esfuerzo en orden a lograr una cuantificación rigurosa del fenómeno - es decir, se trata de algo que requerirá de ulteriores precisiones-, ello no obsta a que sea un punto de partida imprescindible para avanzar hacia una comprensión más cabal de la grave situación de violencia que vive El Salvador en la postguerra. Así pues, lo que aquí se presenta es un primer acercamiento a la magnitud de la violencia en El Salvador, para lo cual nos centramos en dos puntos principales: violencia sobre las personas y violencia sobre las propiedades.

\subsection{Violencia contra las personas}

La violencia, en cuanto acción orientada a agredir física y/o mentalmente a una o varias personas, ocupa un lugar de primera importancia en los registros que lleva la Fiscalía General de la República (FGR). En efecto, como lo ilustra el cuadro 1, para los años 1994, 1995 y 1996 los delitos contra la vida y la integridad personal promediaron los 25 mil casos. Incluso, aunque disminuyeron en aproximadamente unos 6 mil casos en 1995 -respecto a 1994-, al año siguiente experimentaron un nuevo crecimiento -en casi 3 mil casos-. Asimis- 
mo, los delitos contra la vida anduvieron en promedio alrededor de la mitad del total de delitos, lo cual quiere decir, en términos prácticos, que, de cada dos delitos, en uno de ellos estuvo en peligro la integridad física de la víctima.

\section{Cuadro 1 \\ Delitos contra la vida e integridad personal reportados por la Fiscalía General de la República según año.}

\begin{tabular}{cccc}
\hline Año & $\begin{array}{c}\text { Total } \\
\text { de delitos }\end{array}$ & $\begin{array}{c}\text { Total } \\
\text { delitos } \\
\text { contra la vida }\end{array}$ & Porcentaje \\
\hline 1994 & 41,162 & 29,957 & 72.7 \\
1995 & 47,293 & 22,878 & 48.4 \\
1996 & 58,108 & 25,548 & 39.7 \\
\hline
\end{tabular}

Fuente: Elaboración IUDOP-CIDAI en base a registros de la FGR

Pero el cuadro 1 revela otras cosas interesantes de comentar. Por ejemplo, el elevado porcentaje de delitos contra la vida en 1994 (72\%) en relación al total de delitos. En ese entonces, ni la Policía Nacional Civil se había consolidado como una institución capaz de ejercer algún tipo de control sobre todo el territorio nacional ni, lo que es más significativo, el gobiemo salvadoreño había dados muestras de estar preocupado por el problema de la violencia.

En los años siguientes, especialmente en 1996, ambas cosas cambiaron drásticamente en el país: la Policía Nacional Civil no sólo desplegó efectivos en casi todo el territorio nacional -muchas veces en coordinación con tropas del ejército-, sino que el gobiemo del Presidente Armando Calderón Sol lanzó una fuerte campaña en favor de la pena de muerte como mecanismo idóneo para castigar los asesinatos, las violaciones y el secuestro. Esto parece tener alguna relación con la disminución de los delitos contra la vida en el año de 1996, pese a que el total de delitos aumentó, en 1996, en casi 17 mil casos, en comparación a 1994. Es, en definitiva, como si la amenaza gubernamental por aplicar la pena de muerte hubiese sido más eficaz para detener la violencia contra las personas, pero no para controlar otros tipos de violencia.

\subsubsection{Homicidios}

Por otra parte, dentro del rubro "violencia contra las personas" existe una categoría que da una medida más cabal de lo grave que es el problema de la violencia en El Salvador: los homicidios. Como lo revela el cuadro 2, nuestro país fácilmente puede ser considerado como el país más violento de América Latina, muy por encima de Colombia que hasta hace poco se consideró como el poseedor indiscutible de tal distinción. Una lectura optimista de los datos que revelan los "homicidios intencionales" podría sostener que aunque El Salvador 
ha mantenido consistentemente durante 1994 y 1995 su número global de homicidios intencionales — arriba de 7 mil casos - el mismo ha disminuido en 1996 en unos mil casos; ello estaría apuntando, pues, a una tendencia positiva en este apartado de la violencia contra las personas. De algún modo, los datos que ilustran el "total de homicidios" también ponen de manifiesto una reducción en los mismos para el año de 1996. Con todo, las tasas de 117.4 por cada 100 mil habitantes -homicidios intencionales - y de 139 por cada 100 mil habitantes - total de homicidios - son verdaderamente alarmantes e indicativas de los niveles de violencia que imperan en El Salvador de la postguerra.

\section{Cuadro 2}

Cantidad de homicidios y tasas de homicidios calculadas según el registro de la Fiscalía General de la República

\begin{tabular}{|c|c|c|c|c|}
\hline & \multicolumn{2}{|c}{$\begin{array}{c}\text { HOMICIDIOS } \\
\text { INTERNACIONALES }\end{array}$} \\
& \multicolumn{1}{|c|}{$\begin{array}{c}\text { TOTAL DE } \\
\text { HOMICIDIOS }\end{array}$} \\
\hline AÑOS & Número & Tasa bruta & Número & Tasa bruta \\
& & & & \\
1994 & 7,673 & $138.2 / 100$ mil hab. & 9,135 & $164.5 / 100$ mil hab. \\
1995 & 7,877 & $138.9 / 100$ mil hab. & 8,485 & $149.7 / 100$ mil hab. \\
1996 & 6,792 & $117.4 / 100$ mil hab. & 8,047 & $139 / 100$ mil hab. \\
\hline
\end{tabular}

Proyecciones de Población según el Censo Nacional de Población de 1992:

Total nacional $1994=5,552,000$ habitantes.

Total nacional $1995=5,668,600$ habitantes.

Total nacional $1996=5,787,100$ habitantes.

Fuente: Elaboración IUDOP-CIDAI sobre datos de la FGR.

Una hipótesis que manejan varios analistas del país es que la mayor parte de homicidios se producen en las zonas urbanas, especialmente en el Area Metropolitana de San Salvador (AMSS). Para ilustrar esta idea, sirvan los datos del cuadro 3, que recoge información de dos fuentes distintas: el Instituto de Medicina Legal, y alcaldías del AMSS. En términos generales, las tasas de homicidios por cada 100 mil habitantes de ambas fuentes se aproximan bastante entre sí, y tanto los 77.3 homicidios por 100 mil habitantes que Medicina Legal reporta para 1996 como los 84.5 reportados por las alcaldías son indicativos de cómo se concentran en San Salvador y los municipios aledaños los homicidios. 


\section{Cuadro 3}

Número y tasa de homicidios en el AMSS en 1995 y 1996 según distintas fuentes

\begin{tabular}{lccc}
\hline Fuente & Año & Número & $\begin{array}{c}\text { Tasa por } \\
100,000 \text { habs. }\end{array}$ \\
\hline Instituto de Medicina Legal* & 1995 & 1,350 & 89.8 \\
& 1996 & 1,197 & 77.3 \\
$\begin{array}{l}\text { Registros de alcaldías } \\
\text { AMSS** }\end{array}$ & 1995 & 1,460 & 95.4 \\
& 1996 & 1,335 & 84.5 \\
\hline
\end{tabular}

* El IML no incluye a los municipios de Santa Tecla y Antiguo Cuscatlán

** No incluye los registros del municipio de Cuscatancingo

Proyecciones de Población según el Censo Nacional de Población de 1992:

Total AMSS 1995 sin Santa Tecla y Antiguo Cuscatlón =1, 502,602 habitantes.

Total AMSS 1996 sin Santa Tecla y Antiguo Cuscatlón = 1,547,784 habitantes.

Total AMSS sin Cuscatancingo $1995=1,595,612$.

Total AMSS $\sin$ Cuscatancingo $1996=1,643,657$.

No se puede dejar de señalar una consecuencia importante que se sigue de los homicidios: los años de vida perdidos por muerte prematura. El cuadro 4 presenta un estimado del número de años perdidos en 1996 a causa de siete tipos de violencia intencional, entre los que ocupa el primer lugar la muerte por arma de fuego, seguida muy de lejos por el arma blanca y el trauma cráneo encefálico. Como se ve, pues, las herencias de la guerra -utilización de armamento y técnicas de aniquilamiento militares - siguieron provocando pérdidas de vidas humanas cuatro años después de firmados los Acuerdos de Paz.

\section{Cuadro 4}

Años de vida perdidos por muerte prematura en 1996 a causa de violencia intencional según causa de muerte.

\begin{tabular}{|c|c|c|}
\hline Causa de muerte & $\begin{array}{c}\text { Número de años } \\
\text { perdidos }\end{array}$ & Porcentaje \\
\hline Arma de fuego & $92,970.48$ & 52.2 \\
\hline Arma de blanca & $30,365.47$ & 17.0 \\
\hline Trauma cráneo-encefálico & $19,636.58$ & 11.0 \\
\hline Asfixia por estrangulación & $12,775.68$ & 7.2 \\
\hline Politraumatizado & $10,016.77$ & 5.6 \\
\hline Causas indeterminadas & $7,606.33$ & 4.3 \\
\hline Artefactos explosivos & $4,760.34$ & 2.7 \\
\hline Total & $178,131.65$ & 100 \\
\hline
\end{tabular}

Fuente: Elaboración IUDOP-CIDAI 


\subsubsection{Lesiones}

Ciertamente, no siempre la violencia contra las personas se traduce en un homicidio; en la mayoría de casos, las víctimas de la violencia resultan con lesiones de diversa gravedad. Para 1995 y 1996, como lo revelan los datos de la Cruz Roja Salvadoreña, recogidos en el cuadro 5, el total de lesionados a nivel nacional sobrepasó, en ambos años, los 2 mil casos. Y, lo que es particularmente significativo, los lesionados lo fueron o bien como resultado de riñas entre "maras" - las cuales operan principalmente en los centros urbanos - y los asaltos callejeros. Las víctimas de la explosión de artefactos explosivos - pese a haberse incrementado en un poco más de 100 casos en 1996- son pocas en comparación con las que dejan aquéllas, lo cual sugiere, cuando menos, que existen otros focos de violencia urbana no directamente vinculados con la herencia de le guerra. Las "maras" o pandillas juveniles son un ejemplo de ello, en tanto que las mismas no plantean algún tipo de demanda política, sino demandas de naturaleza simbólica y territorial que frecuentemente se vinculan a prácticas delincuenciales, como el robo y la drogadicción.

\begin{tabular}{lcr} 
& $\begin{array}{c}\text { Cuadro 5 } \\
\text { Cruz Roja Salvadoreńa* } \\
\text { Lesiones/total nacional }\end{array}$ & \\
\hline Riñas de "maras" & 1995 & 1996 \\
\hline Asaltos callejeros & 588 & 1528 \\
Artefactos explosivos & 1548 & 1528 \\
Totales & 51 & 159 \\
\hline
\end{tabular}

* Los registros de la Cruz Roja Salvadoreña contemplan información de los principales centros urbanos del país, especialmente del área metropolitana de San Salvador

De todos modos, la Cruz Roja Salvadoreña, aunque recoge información de un enorme valor cualitativo sobre la violencia urbana, se queda corta a la hora de dar cuenta de la totalidad de casos de lesionados como resultado de la violencia. Los datos recabados por la Fiscalía General de la República (cuadro 6) nos dan una medida más completa de la magnitud de las lesiones en El Salvador para los años 1995-1996, así como de las tasas correspondientes. Es preocupante el crecimiento no sólo del total de lesiones en aproximadamente 3 mil casos, de 1995 a 1996, sino su evolución de 212 lesionados por 100 mil habitantes, en 1995, a 261 por 100 mil habitantes en 1996.

Ello pone de manifiesto no sólo que la violencia lejos de disminuir aumenta, sino que también aumenta el número de salvadoreños con algún tipo de trauma físico o mental a consecuencia de algún tipo de agresión. Las repercusiones que 
ello tiene para la convivencia familiar, laboral o profesional todavía no han sido exploradas con suficiente profundidad, pero es indudable que según sea la gravedad de la lesión y sus secuelas así será las dificultades que tendrán que enfrentar la víctima y sus familiares en su convivencia cotidiana.

\section{Cuadro 6}

Fiscalía General de la República

\begin{tabular}{ccc}
\hline Año & Lesiones/total nacional & Tasa de lesiones \\
\hline 1995 & 11,431 & $212 / 100$ mil hab. \\
1996 & 14,352 & $261 / 100$ mil hab. \\
\hline
\end{tabular}

Finalmente, en el cuadro 7, recogemos algunos tipos de violencia -según registros de entrada de causas de la Fiscalía General de la República durante 1995- cuyo impacto psicológico en las víctimas es sumamente importante. Como puede verse, una número significativo de casos tiene que ver con delitos sexuales, entre los que sobresalen las violaciones. No es menos inquietante el número de amenazas registradas, pues en la cotidianidad de los salvadoreños esa forma de violencia tiene un lugar destacado. Más aún, su erradicación es tanto más difícil en cuanto que la gran mayoría de los habitantes de El Salvador no considera que las amenazas - de las que son agentes o víctimas-son un ejercicio de violencia y, mucho menos, que pueden tomarse en algo ilegal.

\section{Cuadro 7}

Fiscalía General de la República

Registro de entrada de causas 1995

\begin{tabular}{|l|r|}
\hline Delito & Total \\
\hline Violación & 1666 \\
Estupro y abuso camal & 46 \\
Abusos deshonestos & 170 \\
Rapto & 491 \\
Secuestro & 126 \\
Coacción & 23 \\
Amenazas & 3650 \\
& 6172 \\
\hline
\end{tabular}

\subsection{Violencia sobre la propiedad}

La violencia, como hemos dicho antes, no sólo se ejerce contra las personas. También los bienes y las propiedades pueden ser afectados por toda la variedad 
de comportamientos agresivos que se asocian a aquélla. $Y$ así como cuando se examina la violencia contra las personas una pregunta clave tiene que ver con el número de muertos y lesionados que aquélla arroja, cuando se examina la violencia contra la propiedad la pregunta por la magnitud de la misma se vuelve ineludible. A continuación presentamos los resultados nacionales urbanos de varias encuestas de victimización realizadas por el IUDOP (cuadro 8) y el número de delitos contra el patrimonio nacional en 1995 y 1996 según la Fiscalía General de la República y la Policía Nacional Civil (cuadro 9).

En lo que se refiere específicamente al rubro de la violencia sobre la propiedad, el cuadro 8 nos muestra, para tres meses y años distintos (febrero de 1993, agosto de 1994 y mayo de 1996) el porcentaje de hogares víctimas de salto en los últimos cuatro meses (correspondientes a la fecha de la encuesta respectiva). Aquí lo importante es que en los cuatro meses anteriores a agosto de 1994 se incrementó, en 5 puntos, el porcentaje de hogares asaltados en relación a los cuatro meses anteriores a febrero de 1993. Mientras que en los cuatro meses anteriores a mayo de 1996 hubo, en relación a los resultados de los dos sondeos previos, una notable disminución en el porcentaje de hogares víctima de asaltos, lo cual seguramente guarda alguna relación no sólo con el endurecimiento de las leyes y el aumento de la vigilancia policial, sino por las medidas de protección de sus hogares implementadas por sectores de las clases medias y altas, las cuales incluyen construcción de portones y rejas de seguridad, sistemas de alarmas y contratación de vigilancia privada.

\section{Cuadro 8}

Resultados nacionales urbanos de encuestas de victimización (En porcentajes)

\begin{tabular}{lccc}
\hline & \multicolumn{3}{c}{ FECHA } \\
\hline RUBRO & Febrero 93 & Agosto 94 & Mayo 1996 \\
$\begin{array}{l}\text { Hogares víctimas de asalto en } \\
\begin{array}{l}\text { los últimos cuatro meses } \\
\text { Hechos en el que la víctima }\end{array}\end{array}$ & 34.5 & 39.5 & 29.5 \\
$\begin{array}{l}\text { resultó lesionada } \\
\text { Hechos denunciados a las } \\
\text { autoridades }\end{array}$ & - & 24.7 & 17.6 \\
\hline
\end{tabular}

Fuentes: Encuestas del Instituto Universitario de Opinión Pública, 1993; 1994 y 1996.

El cuadro 9, recoge los delitos contra la propiedad registrados, para los años de 1995 y 1996, por la Fiscalía General de la República y por la Policía Nacional Civil, respectivamente. En ambos registros, como puede verse, los hurtos y robos sobrepasan el $50 \%$ del total de delitos. Asimismo, lo más importante de destacar es que el robo y hurto de vehículos - tercero en el orden de delitos contra la propiedad - alcanza, en el registro de la Fiscalía General de la Repú- 
blica, un $12.4 \%$ del total de delitos, mientras que en el registro de la policía alcanza un $28.6 \%$. Esta discrepancia puede obedecer no sólo a un incremento en el robo y hurto de vehículos de un año al otro, sino que ese delito suele reportarse, preferentemente, a la policía, que ha asumido como una de sus tareas prioritarias su combate. La falta de registros —de la policía para el año de 1995 y de la Fiscalía para el año de 1996 - impiden hacerse una idea más clara de las razones que explican la discrepancia aludida. De todos modos, ello no obsta para caer en la cuenta de que en El Salvador los delitos contra la propiedad, en 1995 y 1996, se concentraron en el hurto y el robo, y que entre las víctimas ocuparon un lugar importante los propietarios de vehículos automotores.

\section{Cuadro 9}

Delitos contra el patrimonio a nivel nacional en 1995 y 1996 según los registros de la Fiscalía y la Policía

\begin{tabular}{|l|r|r|r|r|}
\hline \multirow{2}{*}{ Tipo de delitos } & \multicolumn{2}{|c|}{ FGR (1995) } & \multicolumn{2}{c|}{ Policía (1996) } \\
\cline { 2 - 5 } & $\mathbf{N}$ & \multicolumn{1}{c|}{$\%$} & $\mathbf{N}$ & $\%$ \\
\hline Hurtos & 4,395 & 24.7 & 4,734 & 33.9 \\
Robos & 5,842 & 32.8 & 5,226 & 37.5 \\
Robo y hurto de vehículos & 2,205 & 12.4 & 3,993 & 28.6 \\
Estafas & 1,578 & 8.9 & n.d. & - \\
Daños & 2,273 & 12.8 & n.d. & - \\
Otros & 1,496 & 8.4 & n.d. & - \\
\hline Total & 17,789 & 100 & 13,953 & 100 \\
\hline
\end{tabular}

\section{Reflexión final}

Los salvadoreños estamos ante una situación de violencia social verdaderamente grave y, lo que es peor, no parecemos damos cuenta de ello. Se trata, entonces, de comenzar por prestarle atención al problema, entenderlo y buscar las mejores soluciones. Pero ello no es fácil, pues ante el tema de la violencia sobran las opiniones, sin que haya sobre ella una visión clara y precisa.

Ante todo, la violencia constituye un desafío para la academia. Teóricamente, no se la ha definido con suficiente claridad, aunque desde la filosofía, la sociología y la psicología se hayan difundido las tesis más diversas sobre la misma. Así, filosóficamente, se puede sostener que la violencia tiene un estatus antropológico irrecusable, por el cual la misma - como una dimensión de poder inscrita en la naturaleza humana - no puede ser eliminada del todo de la convivencia social. Sociológicamente, se puede prestar atención a la estructura social, las clases, las jerarquías y las relaciones de poder que existen entre unos grupos sociales y otros. Desde aquí se puede avanzar hacia la tesis de que la violencia es una exacerbación de esas relaciones de poder, especialmente cuando los grupos económica y políticamente dominantes ejercen la fuerza y la coacción para garantizar y proteger sus privilegios de clase. Psicológicamente, se puede aterri- 
zar en los individuos y su subjetividad, así como en los patrones de interacción que los llevan a reafimarse violentamente ante los otros. Clásicamente, estos han sido los modos de acercarse al problema de la violencia, sin que en ellos se hayan agotado las posibles explicaciones sobre el fenómeno. Las tres perspectivas pueden ser sostenidas con los más diversos argumentos, pero - por eso mismo- ello hace más difícil alcanzar la claridad conceptual necesaria.

Como quiera que sea, la violencia constituye un desafío para todos y cada uno de los miembros de la sociedad salvadoreña. Los habitantes de El Salvador viven en un contexto de violencia permanente, cuyas expresiones más significativas son los homicidios y las lesiones intencionales. Según los datos de la Fiscalía General de la República, en 1996, hubo 8047 homicidios a nivel nacional, es decir, una tasa de 139 muertos por cada 100 mil habitantes; hubo, asimismo, según los registros del Ministerio de Salud, un total de 26192 lesionados, es decir, una tasa de 464 personas agredidas por cada 100 mil habitantes. El frío cálculo numérico nos indica la gravedad de la situación, pues esas tasas de homicidios y lesionados sitúan a nuestro país a la cabeza de los países más violentos de América Latina. Más allá del dato, por supuesto, está la vida diaria de cada salvadoreño, para el cual es sumamente alta la probabilidad de ser agredido o asesinado tanto fuera como dentro de su casa.

Siempre en el terreno de la importancia práctica de la violencia, está el impacto económico de la misma. Impacta a nivel estatal, puesto que, a medida que la situación se vuelve más incontrolable, los gastos presupuestarios asignados a instituciones como la Policía Nacional Civil o la Fiscalía General de la República se vuelven insuficientes, por lo que es necesario desviar más recursos hacia ellas. Asimismo, el sistema de salud, por el cual pasa un buen número de lesionados - muchos de ellos a punto de fallecer-, invierte una parte importante de sus recursos - ciertamente insuficientes - en la atención de esos casos. Pero también los agentes privados invierten en su seguridad para protegerse de la violencia: rejas, balcones, vigilancia privada, seguros de autos. Un número importante de familias ha perdido sumas considerables por asaltos a sus casas o por robos de vehículos. Otras, o han perdido a un miembro que aportaba recursos para el sostenimiento del grupo familiar o se ven de pronto con un lesionado que drena recursos del hogar para su atención médica o su manutención.

Todo ello no ha sido suficientemente calculado, por lo cual no contamos con una cifra veraz que nos diga cuánto de los recursos económicos del país, estatales y privados, son absorbidos por el agujero negro de la violencia y qué porcentaje del PIB representan esos costos. Estamos lejos de conocer, además, algo sumamente importante: cuánto cuesta a la sociedad perder, sea por homicidio o por lesión, miembros suyos cuya formación técnica y profesional ha supuesto una inversión económica y cultural considerable, así como lo que costaría formar a personas con similar nivel de conocimientos.

Dicho de otra forma, para acercamos con un mínimo de seriedad no basta con contar con precisión el número de muertos y lesionados. Es necesario no sólo establecer las causas de los asesinatos y las lesiones, sino indagar acerca de cuánto invierten los actores privados en su seguridad, en la atención de miem- 
bros del hogar lesionados y la reducción de ingresos que supone perder a uno de los suyos. Sin esta contabilidad básica la discusión sobre la violencia carecerá de asidero en la realidad.

Una alcanzado un conocimiento mínimamente riguroso de la violencia, se tiene que pasar a su combate, el cual no implica necesariamente el endurecimiento de las sanciones penales. Se trata, ante todo, de auxiliarse de la medicina y hacer estudios epidemiológicos que permitan hacer un mapeo de los factores que se asocian a los diversos actos delictivos. Hecho este diagnóstico, llegará la hora de pasar a las soluciones no del macro problema de la violencia, sino de aquellos factores de corto, mediano y largo plazo que es necesario controlar o erradicar. Se trata, aquí, de hacer políticas públicas orientadas a resolver los problemas específicos detectados por estudios epidemiológicos científicamente llevados a cabo. Esta última parte, una de las más importantes en el combate de la violencia, requerirá —de parte de empresarios, políticos, académicos y ciudadanos en general - no sólo de una preocupación real por el problema de la violencia, sino también de una disposición sin límites para coordinar esfuerzos que permitan hacer un trabajo más eficaz en orden a disminuir los niveles de violencia en El Salvador.

\section{Notas:}

1. Incluso, obviando las limitaciones del proceso, se ha presentado a El Salvador un modelo de lo que es un proceso exitoso de reinserción de ex combatientes (especialmente de la ex guerrilla) a la vida civil. Y es que ni en Perú ni Colombia, los casos que más se compara con El Salvador, el gobiemo ha diseñado un programa para desmovilizar y reinsertar a los ex combatientes, limitándose a diseñara políticas de asentamiento o reasentamiento - lo cual incluye entrega de tierras, capacitación y asistencia crediticiaa las poblaciones afectadas (o desplazadas) por la situación de conflicto. La experiencia que más se asemeja a la salvadoreña es la guatemalteca, con la excepción de que los planes de demovilización y reinserción de ex ombatientes apenas ha iniciado.

2. Lechner, N., "La problemática invocación de la sociedad civil". Revista centroamericana de cultura política, No. 4, junio de 1995, p, 5.

3. Sólo por mencionar un ejemplo, en la década de los 70 los pobladores de tugurios se organizaron en la Unión de Pobladores de Tugurios (UPT), afiliada al Bloque Popular Revolucionario (BPR). Pues bien, en su gran mayoría la UPT estaba formada por jóvenes de entre 15 y 25 años, muchos de los cuales fueron asesinados a principios de la década de los 80 o se incorporaron al FMLN. El Movimiento Estudiantil de Estudiantes de Secundaria (MERS), también perteneciente al BPR, estaba formado por adolescentes que corrieron la misma suerte que los miembros de la UPT.

4. Cfr. "El problema de las maras". El Salvador Proceso, No. 776, septiembre de 1995

5. Cfr. Instituto Universitario de Opinión Pública (IUDOP), "Solidaridad y violencia. Los jóvenes pandilleros en el Gran San Salvador”. ECA, No. 585-586, julio-agosto de 1997, pp. 695-710,

6. Según datos del P.A.H.O Research Procotocol, en 1995, todas las ciudades de Colombia tenían, en conjunto, una tasa de homicidios por 100 mil habitantes de 110.4, mientras que la de El Salvador era de 136.5. 


\section{Bibliografia}

Alvarenga, P., Cultura y ética de la violencia. El Salvador, 1880-1932. San José, EDUCA, 1996.

Binford, L., El Mozote, vidas y memorias. San Salvador, UCAVEd., 1997.

Centro de Información, Documentación y Apoyo a la Investigación (CIDAI), "El Salvador en 1996: política, economía y sociedad". ECA, $\mathbf{N}^{\circ}$ 579-580, enero-febrero de 1997, pp. 25-55.

Cordova Mancías, R., El Salvador: las negociaciones de paz y los retos de la postguerra. San Salvador, IDELA, 1993.

Escobar, F.A., "Por mi madre vivo y por mi barrio muero. Una aproximación al fenómeno de las maras". ECA, No. 570, pp. 327-350.

Foucault, M., Vigilar y castigar. Nacimiento de la prisión. México, siglo XXI, 1993.

Foucault, M., Las palabras y las cosas. Una arqueologla de las ciencias humanas. México, siglo XXI, 1991.

González, L. A., "Reflexiones ético-políticas sobre la pena de muerte". ECA, No., 558, abril de 1995, pp. 386-390

González, L. A., "Reflexiones sobre la violencia”. ECA, No. 570, abril de 1996, pp. 365 368

González, L. A., Cruz, J.M. (Eds.), Sociedad y violencia. El Salvador en la postguerra. San Salvador, IUDOP-CIDAI, sf

Guerra Maceo, C., "Sociedad, violencia y salud: una agenda para la democracia". En Conferencia interamericana sobre sociedad, violencia y salud Washington, OPS, 1994

Instituto de Naciones Unidas para el Desarrollo Social, Estados de desorden. Los efectos sociales de la globalización. Londres, UNRISD, 1995

Instituto Universitario de Opinión Pública (IUDOP), "La violencia en El Salvador”. ECA, No. 569, marzo de 1996, pp.240-249. 